\title{
Publisher Correction to: Development of the Asia Pacific Consortium on Osteoporosis (APCO) framework: clinical standards of care for the screening, diagnosis, and management of osteoporosis in the Asia-Pacific region
}



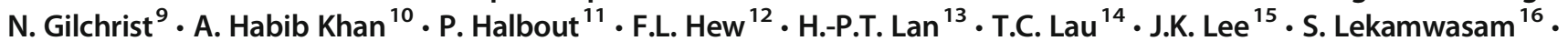 \\ G. Lyubomirsky ${ }^{17}$ • L.B. Mercado-Asis ${ }^{18}$ - A. Mithal ${ }^{19}$ - T.V. Nguyen ${ }^{20}$ • D. Pandey ${ }^{21}$ - I.R. Reid ${ }^{22}$. A. Suzuki ${ }^{23}$. $^{2}$ \\ T.T. Chit ${ }^{24}$ K.L. Tiu ${ }^{25}$. T. Valleenukul ${ }^{26}$ - C.K. Yung ${ }^{27}$ - Y.L. Zhao ${ }^{28}$ on behalf of the Asia Pacific Consortium on \\ Osteoporosis (APCO)
}

Published online: 27 May 2021

(C) The Author(s) 2021

\section{Correction to: Osteoporosis International} https://doi.org/10.1007/s00198-020-05742-0

The original version of this article, published on 27 January 2021, unfortunately contained a mistake.

The references of the article were incorrectly incorporated.

The publishers apologize for the mistake

The original article has been corrected.
Open Access This article is licensed under a Creative Commons Attribution-NonCommercial 4.0 International License, which permits any non-commercial use, sharing, adaptation, distribution and reproduction in any medium or format, as long as you give appropriate credit to the original author(s) and the source, provide a link to the Creative Commons licence, and indicate if changes were made. The images or other third party material in this article are included in the article's Creative Commons licence, unless indicated otherwise in a credit line to the material. If material is not included in the article's Creative Commons licence and your intended use is not permitted by statutory regulation or exceeds the permitted use, you will need to obtain permission directly from the copyright holder. To view a copy of this licence, visit http:// creativecommons.org/licenses/by-nc/4.0/.

Publisher's note Springer Nature remains neutral with regard to jurisdictional claims in published maps and institutional affiliations.
The online version of the original article can be found at https://doi.org/ $10.1007 / \mathrm{s} 00198-020-05742-0$

M. Chandran

manju.chandran@singhealth.com.sg

Extended author information available on the last page of the article 


\section{Affiliations}

M. Chandran ${ }^{1}$ - P.J. Mitchell ${ }^{2} \cdot$ T. Amphansap ${ }^{3} \cdot$ S.K. Bhadada ${ }^{4} \cdot$ M. Chadha ${ }^{5} \cdot$ D.-C. Chan ${ }^{6} \cdot$ Y.-S. Chung ${ }^{7} \cdot$ P. Ebeling ${ }^{8}$.

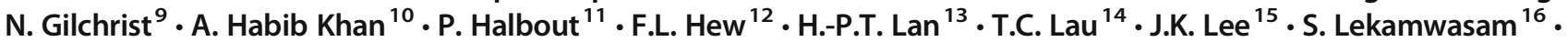
G. Lyubomirsky ${ }^{17}$ - L.B. Mercado-Asis ${ }^{18}$ - A. Mithal ${ }^{19}$ - T.V. Nguyen ${ }^{20} \cdot$ D. Pandey ${ }^{21} \cdot$ I.R. Reid ${ }^{22} \cdot$ A. Suzuki ${ }^{23}$. T.T. Chit ${ }^{24}$ - K.L. Tiu ${ }^{25}$. T. Valleenukul ${ }^{26}$. C.K. Yung ${ }^{27}$ - Y.L. Zhao ${ }^{28}$ on behalf of the Asia Pacific Consortium on Osteoporosis (APCO)

1 Department of Endocrinology, Osteoporosis and Bone Metabolism Unit, Singapore General Hospital, 20, College Road, Academia, Singapore 169856, Singapore

2 Synthesis Medical NZ Limited, Pukekohe, Auckland, New Zealand

3 Department of Orthopedics, Police General Hospital, Bangkok, Thailand

4 Department of Endocrinology, Postgraduate Institute of Medical Education and Research, Chandigarh, India

5 Department of Endocrinology, Hinduja Hospital and Research Centre, Mumbai, India

6 Internal Medicine, National University Hospital Chu-Tung Branch, Chinese Taipei, Taiwan

7 Department of Endocrinology and Metabolism, Ajou University School of Medicine, Suwon, South Korea

8 Department of Medicine in the School of Clinical Sciences, Monash Health, Melbourne, Australia

9 Canterbury District Health Board, Christchurch, New Zealand

10 Section of Chemical Pathology, Department of Pathology and Laboratory Medicine, Aga Khan University, Karachi, Pakistan

11 International Osteoporosis Foundation, Nyon, Switzerland

12 Department of Medicine, Subang Jaya Medical Centre, Subang Jaya, Malaysia

13 Musculoskeletal and Metabolic Unit, Biomedical Research Center, Pham Ngoc Thach University of Medicine, Bone and Muscle Research Group, Ton Duc Thang University, Ho Chi Minh City, Vietnam

14 Division of Rheumatology, Department of Medicine, National University Hospital, Singapore, Singapore
15 Department of Orthopedics, Beacon International Specialist Centre, Petaling Jaya, Malaysia

16 Faculty of Medicine, University of Ruhuna, Galle, Sri Lanka

17 Osteoporosis Australia, Sydney, Australia

18 Faculty of Medicine and Surgery, University of Santo Tomas, Manila, Philippines

19 Endocrinology, Diabetes Division, Mithal, M. Max Healthcare Pan-Max, Gurgaon, India

20 Genetics and Epidemiology of Osteoporosis Laboratory, Bone Biology Division, Garvan Institute of Medical Reseach, Sydney, Australia

21 Department of Orthopaedics, National Trauma Centre, Kathmandu, Nepal

22 Faculty of Medical and Health Sciences, University of Auckland, Auckland, New Zealand

23 Department of Endocrinology, School of Medicine, Fujita Health University, Toyoake, Japan

24 East Yangon General Hospital, Yangon, Myanmar

25 Polytrauma and Fragility Fracture Team, Department of Orthopaedics and Traumatology, Queen Elizabeth Hospital, Hong Kong, SAR, China

26 Department of Orthopedics, Bhumibol Adulyadej Hospital, Bangkok, Thailand

27 Department of Endocrinology and Patient Safety Unit, Raja Isteri Pengiran Anak Saleha Hospital, Bandar Seri Begawan, Brunei Darussalam

28 Department of Obstetrics and Gynecology, Beijing United Family Hospital, Beijing, China 